\title{
FOOD VALUE CHAIN TRANSFORMATION IN DEVELOPING REGIONS
}

\section{Thomas Reardon and Bart Minten}

The "food system" is defined by Reardon et al. (2019) as a "dendritic cluster" of value chains linking the following:

1. Input suppliers to farmers ("farm input value chains").

2. Farmers upstream to wholesalers and processors midstream, to retailers then consumers downstream ("farm output value chains").

3. "Lateral service value chains" to all segments of the above two value chains (such as the transport supply chain as input to the wholesale segment of the output value chain).

4. R\&D\&E (research, development, and extension) suppliers to all the segments of the above value chains (such as the generation of new crop varieties by breeders in research institutes, to extension agents to farmers).

In this chapter, for brevity, we focus on the output value chains, but the conceptual framework and most trends are also relevant to the input value chains, the lateral service value chains, and $R \& D \& E$ suppliers. Output value chains in developing countries have transformed over the past 50 years but particularly quickly only in the past 25 years. In many countries the transformation of value chains has been abrupt, not gradual. Reardon and Timmer (2014), illustrating with Asian evidence, explain the drivers of this rapid change as a confluence of the following three sets of interlinked transformations:

1. Downstream demand side change (urbanization and diet change) "pulling" system transformation.

2. Midstream/downstream change (in the structure and conduct of retail, wholesale, logistics, and processing) “intermediating" system transformation.

3. Upstream change (intensification, diversification, and commercialization of farming) "feeding" system transformation. 
This chapter focuses on the downstream and midstream transformations (leaving to other chapters the treatment of upstream farm sector change). The chapter proceeds as follows. The next section lays out a heuristic conceptual framework of the product cycle and stages of transformation of the food value chains (FVCs). Then the main lines of the evidence concerning rapid transformation of FVCs in the developing region are traced. The three waves of research on the transformation of FVCs mainly over the past 70 years are discussed. The chapter concludes with an assessment of the literature and its gaps.

\section{A Heuristic Conceptual Framework Regarding the Stages of Transformation of Food Value Chains and the Product Cycle}

We provide a simple heuristic framework to classify and discuss the transformation of FVCs. We start with the traditional "structure-conductperformance" model to facilitate a "stylized facts" description of the stages of transformation of FVCs (de Figueirêdo, Meuwissen, and Oude Lansink 2014). That framework is neutral with respect to the product, but one encounters products in different phases of their evolution in the market. Thus we also discuss the concept of the "product cycle," which classifies products and thus FVCs. Finally, we combine these first two concepts by presenting a taxonomy of FVC transformation in three stages: traditional, transitional, and modern. The taxonomy is necessarily, for our purposes, heuristic, broad brushstroke, and simplifying, setting aside substantial nuance and heterogeneity across countries and products in the empirical reality.

\section{Structure-Conduct-Performance}

An "industry" can be equated here with a given food value chain, such as the rice value chain from rice farm to rice retailer. The framework's application to an FVC has the three sets of analytical questions: the structure, the conduct, and the performance of the FVC.

\section{Structure of the Food Value Chain}

The structure (in an industrial organization sense) of the FVC can be seen from several angles. First, it can be viewed "chain-wide":

1. What are the number of segments of the FVC and thus what we call its "intermediation length"? For example, the elimination of a segment, 
such as wholesalers between retailers and growers, is "disintermediation" and reduces the intermediation length.

2. What is the FVC's "spatial length" (and geographical orientation)? For example, is it a long chain stretching from distant rural areas to cities, or a short local chain? Is it rural to rural, or urban to rural, or rural to urban? Is it domestic or international?

3. What is the distribution across the segments of the chain of the formation of costs and value-added? This can be thought of as "cross-segment concentration." Viewed another way, what is the share of the postfarmgate segments (and its complement, the share of farmers) in the total value of output of the FVC?

Second, structure can be viewed per segment:

1. How concentrated (over firms) is a given segment (such as measured by the Gini coefficient of, for example, processing firms in the FVC)? Another way to look at this is the share of the largest scale stratum of the actors in a segment in the total output of the segment. For example, what share do large mango farms have in the total output of mangoes in a province in Indonesia (compared with medium and small farms)? The share of output can differ from the share of a stratum in the number of firms or farms in that segment. For example, Qanti et al. (2017) showed that although marginal or "backyard" mango farms constitute 80 percent of mango farms on Java, they control only 20 percent of the output; the 10 percent of farms that are medium-sized control 60 percent of the output.

2. How specific is a given segment's actors to the product of that FVC versus supplying products or services "horizontally" across a number of product FVCs? For example, the vegetable trucks of the logistic segment of the tomato FVC may also carry cucumbers for the cucumber FVC. So vegetable trucks are both a (vertical) segment in one vegetable FVC but also a shared segment across a number of vegetable FVCs.

But there can also be "asset specificity" for a segment. This term is usually used in the new institutional economics (NIE) literature to indicate, say, a piece of equipment that a firm has to buy to participate in a specialized supply chain, such as an ultra-high temperature (UHT) milk processor to supply milk to the Tetrapak packaged sterile milk market in Brazil (Farina et al. 2005). That machine is not of use for other 
purposes, so buying it means locking part of the firm's capital into that particular FVC. That can also go for products. A modern meat-cutting machine can be calibrated to process a number of different ruminant carcasses but cannot be used for processing fish into fish fillets. So the machine is specific to the ruminant FVCs, perhaps used multifunctionally across those meat chains, but not used for the fish FVC.

Similarly, a "trader" (in the commerce segment) might trade not just in maize but also in soy, such as in Nigeria (Liverpool-Tasie et al. 2017). But a milk trader might only trade in milk due to asset specificity of his or her vehicle (such as a tanker truck) or equipment (cold tank). Agglomerations of actors can also serve across FVCs. A good case is a wholesale market.

3. What is the spatial distribution of the actors in each segment? Are the firms or farms clustered or dispersed? Is this correlated with firm scale and thus with concentration in the industrial organization sense? An example is whether small dairy farms tend to be concentrated in hilly areas and larger farms in valley bottomland, or whether large feed mills are peri-urban and small feed mills are scattered in rural areas.

4. What is the capital ownership pattern, such as what share of the capital is foreign owned, or collectively owned?

\section{Conduct of the Food Value Chain}

The conduct or behavior of the FVC can be seen from several angles. First, what is the technology used by producers? Producers are the actors in all segments of the FVC_-from input producers and sellers, to farmers, to wholesalers, retailers, and logistics agents who produce services, and processors who produce (food) manufactures. Technology is assessed via three measures: (1) the ratio of productive factors used, such as the intensity of labor use and capital per unit of output-for example, a supermarket may be more capital intensive than a traditional retailer; (2) the intensity and types of intermediate inputs (such as types of milk used to make cheese); and (3) the scale of production of the actor.

Second, what organization is used by farms and firms to produce, to buy inputs, and to market outputs? To what degree do firms and farms in a given segment vertically integrate (such as a processor also having its own farms or its own retail shops) versus acquire inputs or marketing services from others? To what degree do firms and farms horizontally cluster in cooperatives 
or other groupings? Is that for production or for input procurement or for marketing?

Third, what institutions do farms and firms in the segment (and between segments of the FVC) use to organize their purchase of inputs and sale of outputs? In general, institutions are used to coordinate intersegment relations and impose requirements on suppliers. To what degree do firms and farms mediate their intersegment relations with contracts? For example, how prevalent is contract farming by processors? Do public standards for product quality and safety regulate suppliers in the food value chain? Do midstream and downstream firms such as processors and retailers impose private standards on suppliers?

Fourth, what is the supply and demand of facilitating lateral supply chain services such as finance and information to and from the segments of the FVC? For example, FVC financial conduct analysis examines the sources of and destinations of finance to and from the actors in each segment and between the segments of the FVC. The types of finance by FVC actors include: value-chain finance, and in particular, buyers' credit to suppliers and suppliers' credit to clients; self-finance by the FVC actor; and credit that is not predicated on value-chain relationships, such as a bank loan or microcredit.

\section{Performance of the Food Value Chain}

As with structure and conduct, the performance of the FVC can be seen in terms of the FVC as a whole or of the specific segments (such as the performance of the farm segment per se). But both of these can be analyzed along similar axes, including but not limited to (1) the efficiency of the whole chain, which can include the marketing margin and price integration analysis; (2) the equity of the chain or its segments, measured for example in concentration of income, inclusion of the poor and disadvantaged (as producers or consumers or zones), and adequacy of producer prices and affordability of consumer prices; and (3) externality effects of the FVC, such as on nutrition and the environment.

\section{Product Cycle}

The product cycle is a concept from classical economists such as Ricardo (1817) and then formalized as part of a link to trade theory by Vernon (1966; 1979). Translated into the context of the agrifood economy, the essential idea is that a product has a life cycle that starts as a new product or niche, then that niche product is commoditized into a bulk widely distributed product, 
perhaps growing and diffusing over national markets, until it reaches "maturity." At the latter point its profitability has been competed down, and it either declines or "dies" or transitions into differentiated products that themselves are again niche products and grow into commodities.

We can think of the product cycle evolution as driven by the "Cochrane's treadmill" (Cochrane 1979), where suppliers enter at each stage and compete down the profit, with the innovator driving the product to the next stage of the product cycle. The first step is the product's introduction into a local market as a niche product. Then, as its production is increased and it is marketed more broadly (beyond the local market), its price is driven down, and it becomes a bulk commodity. Competition drives innovation to create differentiated products from the commodity base. These innovations can be, for example, in variety, color, taste, size, type or degree of processing, packaging, and so on. Each differentiated product becomes again a niche and the cycle continues by the drive to commoditize it.

An example is the product that used to be called a Chinese gooseberry, a niche fruit grown locally in China's mountains. In the second half of the 20th century it was renamed "kiwi fruit" by New Zealanders and the green variety grown extensively throughout the world as a bulk commodity. It was then bred by New Zealanders into sweeter varieties, such as the golden kiwi-a differentiated product that is sweeter and with edible skin. The golden kiwi is now being "commoditized" such as with a recent shift to mass production of it in Italy and California.

\section{Three Stages of FVC Transformation}

We conceive of three stages of transformation of the food value chain (Reardon et al. 2019). These stages are functions of characteristics of the structure and conduct of the FVC as well as the phase of the product cycle.

\section{The Traditional Stage}

In the traditional stage, the following patterns are common. The reader could imagine in current time cereals or dairy in rural village markets in Ethiopia and Nepal, or food markets in most developing regions in the 1970s, or such markets in the United States in the 1920s and 1930s. First, in terms of structure, traditional FVCs are spatially short because the urban share of the population in the food market is low. They are also intermediationally short because much of the market is in the rural area and even the same village. The 
share of grains and other staples in the food economy is very high: there is relatively little production of nongrain products, hence few supply chains for them, except in pockets of traditional cash crops. The share of value-added in postharvest segments of the FVCs is small: home processing reigns, and the wholesale and logistic sectors are small because food is not moved far. Most of the segments are fragmented. Concentration is mainly observed where governments assured grain supply to emerging urban populations at subsidized prices via parastatals.

Second, in terms of conduct, as the bulk of the food system is in niche phase for nongrains and niche-to-commodity phase for grains, there is little quality differentiation, standards, or economies of scope. Technologies are labor intensive per unit of output. Enterprise scale is tiny. Spot market relations dominate food value chains; contracts are not used.

\section{The Transitional Stage}

In the transitional stage, the following patterns are common. The reader could imagine in current time aquaculture fish, teff, and maize into urban markets in Bangladesh, Ethiopia, and Tanzania respectively, or food markets in the United States in the 1940s through the 1960s. First, in terms of structure, transitional FVCs are spatially long because the urban share of the population in the food market is moderately high. The exception, where short supply chains still dominate, is in highly perishable products such as leafy greens and farmed fish and dairy. Food value chains are intermediationally long as many small and medium-scale actors in the midstream of the FVCs emerge to add value and move food from rural areas to urban areas. In the transitional phase the share of value-added in postharvest segments of the FVCs is moderately large as wholesale, processing, and logistics sectors have blossomed.

Governments have by the transitional stage largely dismantled output and input parastatals and private firms, especially small and medium-sized enterprises (SMEs), have flooded in, as part of what Reardon (2015) calls a J-curve of concentration: in the traditional stage, there is moderate concentration (parastatals in the public sector alongside a fragmented "parallel market" private sector). Then, with liberalization and privatization of parastatals (in the 1980s and 1990s in developing regions), there is deconcentration with the proliferation of SMEs. By the transitional stage the share of grains and other staples in the food economy is now a minority share. Bennett's Law (1941)stating that when incomes increase, people consume relatively fewer starchy staples and relatively more nutrient-dense (and more expensive) foods-in 
consumption and diversification in farming beyond grains has radically increased production of and FVCs in animal and horticultural products.

Second, in terms of conduct, the bulk of the food system is by the transitional stage in a major shift from the niche to the commodity phase of the product cycle. There is still little quality differentiation, but public standards have started to emerge for grades and quality, and in some cases for product safety. The exception is mostly on the side of value-added, as purchasedprocessed foods and differentiated products for grains (convenience foods and increases in quality) develop rapidly in this stage.

Technologies are still labor intensive, but machine use has emerged in farming and in the rest of the food value chain. For example, home processing such as hand pounding of grain found in the traditional phase has now given way to the proliferation of SMEs, milling companies, alongside a few emerging large-scale companies. SMEs also start playing a bigger role in logistics and wholesale. Spot market relations still dominate, but in a few cases contracts are beginning to emerge.

\section{The Modern Stage}

In the modern stage, the following patterns are common. The reader could imagine in current time food value chains for Senegal mangoes into export markets, rice into the main urban markets in China, and dairy products in Brazil, as well as US food markets in the 1970s, 1980s, and beyond. First, in terms of structure, modern FVCs are spatially long as the urban share is high. Even perishable products such as poultry and dairy and vegetables are by this stage produced far from cities and shipped frozen, chilled, packed, and so on. (But in the most advanced modern stages, there is a renaissance of peri-urban production of some of these products, such as in vertical horticulture.)

By the modern stage, food value chains have become intermediationally short with a trend toward "disintermediation" - as supermarkets and large processors transact directly between themselves and in some cases buy direct from farms. The right-hand side of the $\mathbf{J}$-curve noted earlier has occurred, with substantial concentration in all segments at least upstream and downstream from farms, as well as in the farm sector in some countries. The SMEs that remain stayed competitive through product differentiation or a shield of high transaction costs (such as those in the hinterlands). Foreign direct investment (FDI) liberalization started in the transition stage has by the modern stage caused widespread multinationalization of a number of FVC segments. 
The wholesale sector has evolved to be off-market (outside wholesale markets) with the rise of large logistics and wholesale firms. In the transitional phase the share of value-added in postharvest segments of the FVCs is large (in the United States around 90 percent) in long and complex supply chains. The "food service sector" such as fast-food chains has increased to a substantial share of the food economy (from a modest share in the transitional stage and a tiny share in the traditional stages). By the modern stage, the share of grains and other staples in the food economy is now a small share of overall food, about a quarter or less. Nongrain supply chains and processed food FVCs dominate the total food sector.

Second, in terms of conduct, the bulk of the food system is by the modern stage in a major shift from the commodity to the differentiated products phase of the product cycle. There is now substantial quality differentiation, and private standards for quality and in some cases safety have emerged to begin to eclipse public standards (Henson and Reardon 2005), such as occurred in the dairy sector in Brazil in the 1990s (Farina et al. 2005). Technologies are now largely capital intensive — that is, mechanized all along the FVC. Information-based systems (such as smart chips in packaging and logistics and drones in agriculture) have emerged. Spot market relations are relegated to some sectors like fruits and vegetables, but in meats, grains and dairy contracts have come to dominate.

\section{Synthesis of Stages of Transformation}

A synthesis of the features of the food economy in these three different stages of food value chain transformation is shown in Table 12.1. We see significant differences over the three stages in the urban share in food markets, the share of grain and staples, seasonality, the importance of the food service sector, and the stage in the product cycle as well as the reach of the FVC, which moves overall from local niche products in the traditional FVC to globalized differentiated products in the modern FVC.

The FVC lengthens in spatial and intermediation terms with transformation. Significant change is also seen in value-addition (from low to high) and concentration (from moderate, to low, to high) over the three different stages of FVC transformation (Table 12.2). Conduct changes from low-quality demands, spot market trade, and labor-intensive technologies in traditional FVCs to high-quality differentiation, the wide use of contracts, and capitalintensive technologies in modern FVCs. 
TABLE 12.1 Synthesis of features of the food economy for different stages of food value chains (FVC)

\begin{tabular}{llll}
\hline $\begin{array}{l}\text { Characteristics } \\
\text { of the food economy }\end{array}$ & Traditional FVC & Transitional FVC & Modern FVC \\
\hline Urban share in food market & Low & Medium & High \\
Share of grains and staples & High & Medium & Low \\
Seasonality & High & Medium & Low \\
Food service sector & Small & Modest & Large \\
Reach FVC & Local & National & Global \\
Product cycle & Local niche & National commodity & Differentiated product \\
\hline
\end{tabular}

Source: Authors.

TABLE 12.2 Synthesis of features of structure and conduct for different stages of food value chain (FVC) transformation

\begin{tabular}{llll}
\hline $\begin{array}{l}\text { Characteristics of structure } \\
\text { and conduct }\end{array}$ & Traditional FVC & Transitional FVC & Modern FVC \\
\hline $\begin{array}{l}\text { Structure } \\
\text { Spatial length FVC }\end{array}$ & Short & Long & Long \\
Intermediation length FVC & Short & Long & Short \\
Value-addition & Low & Medium & Large \\
Concentration & Moderate & Low (parastatals; large & High (private large- \\
& & number of small and & scale food industry \\
& & medium-sized enter- & firms) \\
Conduct & & prises) & \\
Quality differentiation & Low & Low & High \\
Quality and safety standards & Few & Public & Private \\
Technologies & Labor-intensive & Labor-intensive & Capital-intensive \\
Contracts & Spot markets only & Spot markets dominate; & Spot markets small; \\
& & emergence of contracts & contracts dominate \\
\hline
\end{tabular}

Source: Authors.

Table 12.3 focuses on the midstream and downstream segments. It shows that traditional FVCs are dominated by domestic processing and fragmented wholesale and retail markets. In transitional FVCs, the public sector takes a more important role for the organization of midstream and downstream segments, but we also note a fast proliferation of small and medium-sized enterprises in this stage. Modern FVCs see consolidation and concentration with large private supermarkets becoming dominant players in this stage. 
TABLE 12.3 Synthesis of features of midstream and downstream segments for different stages of food value chain (FVC) transformation

\begin{tabular}{llll}
\hline Activities & Traditional FVC & Transitional FVC & Modern FVC \\
\hline $\begin{array}{l}\text { Midstream pro- } \\
\text { cessing }\end{array}$ & Mostly domestic & $\begin{array}{l}\text { Parastatals and proliferation } \\
\text { of small and medium-sized } \\
\text { enterprises }\end{array}$ & $\begin{array}{l}\text { Consolidation of private } \\
\text { sector }\end{array}$ \\
$\begin{array}{l}\text { Midstream whole- } \\
\text { sale/logistics }\end{array}$ & $\begin{array}{l}\text { Fragmented whole- } \\
\text { sale markets }\end{array}$ & $\begin{array}{l}\text { Publicly run wholesale } \\
\text { markets (with private whole- } \\
\text { salers) }\end{array}$ & $\begin{array}{l}\text { Concentration; dedicated } \\
\text { wholesalers; large-scale } \\
\text { logistics firms; direct } \\
\text { linkages of retail firms }\end{array}$ \\
Downstream retail & Fragmented & $\begin{array}{l}\text { Small retail shops dominant; } \\
\text { government parastatal re- } \\
\text { tailing; emergence of private } \\
\text { supermarkets }\end{array}$ & $\begin{array}{l}\text { Private supermarkets } \\
\text { dominant; modernization } \\
\text { of procurement systems } \\
\text { of supermarkets }\end{array}$ \\
\hline
\end{tabular}

Source: Authors.

\section{Evidence Concerning the Rapid Transformation of FVCs in Developing Regions}

While the transformation from traditional to transitional to modern FVCs took about 100 years in the United States and western Europe, today's developing regions have in the main made the step to transitional in 20 years, and the frontrunners the step to emerging modern FVCs in 20 to 30 years. The two surprises are that the transformation is in its essence similar to what happened in the United States, just that it has been far faster, nearly abrupt and sudden, in the developing regions. A fitting image is a tidal wave, which is a small ripple in the ocean for a thousand miles then wells up as it comes to the continental shelf. That is the shape of the change in the developing world's food economy. The main reason FVCs changed so fast in developing regions was that there was a confluence of changes that were mutually reinforcing, magnifying, and accelerating-a coevolution of the different pieces. We explore that confluence from two angles.

On the one hand, there were systemic changes, which we classify as (1) "meta conditioners" (change in policy and transport/communications, urbanization, and change in diets) that spurred and facilitated the changes in the FVC segments; and (2) downstream and midstream segment transformations (in retail, processing, wholesale, logistics). We do not treat the upstream change in farms and input systems; those are covered in other chapters. On the other hand, there are a number of cases of local confluences of transformation within or over segments. Below we discuss two such cases: in potato cold storages in India and teff wholesale, processing, and transport in Ethiopia. 
These episodes provide a deep understanding of why and how FVCs are changing so very fast.

\section{Meta Conditioners and Downstream Pull Forces}

\section{Policy and Infrastructure}

Policy liberalization and privatization occurred during the 1980s through the 2000 s as part of transitions away from administered food economies in "transition" countries such as China and Viet Nam as well as "structural adjustment programs" in most of the developing countries in Africa, Asia, and Latin America. Food procurement and distribution parastatals were largely privatized, and internal and external trade in food at least partially liberalized. This spurred the spread both of small and medium-sized enterprises as well as the entry of modern firms via both foreign direct investment and domestic investments. The latter led to the spread of large processors, supermarkets, and fast food chains. FDI liberalization was particularly important as a key inducement to this process.

Infrastructural investment has encouraged lengthening of supply chains and transformation in midstream and downstream segments. Hard infrastructure encourages the development of FVCs. Combined with rising urban demand, infrastructural investment has encouraged private investments by SMEs in the midstream of value chains, such as by teff millers, transporters, and retailers in Ethiopia. Small farmer access to markets is conditioned by infrastructure and distance to market. Barrett (2008) found the latter much more influential than macroeconomic and trade policies on small farmer participation in markets. Stifel, Minten, and Koru (2016) show a doubling of commercial surplus for farmers connected to a market compared with more remote farmers.

Communication access to information has increased significantly with the widespread availability of mobile phones (Nakasone, Torero, and Minten 2014). A large share of farmers in the commercial areas, ranging from a high of 97 percent in China to a low of 27 percent in Ethiopia, owned mobile phones at the time of the survey (around 2010). Taking a simple average of crops and countries in Asia, the data show that almost a quarter of farmers in commercial zones reached a price agreement by phone in their last transaction (Nakasone, Torero, and Minten 2014). For rice and potato supply chains in Dhaka, rice chains in Beijing, and potato chains in Delhi, almost all farmers 
who used phones contacted multiple traders before engaging in a transaction. Overall, 40 percent of staple suppliers in these rural-urban supply chains had contacted multiple buyers by phone before their last transaction (Reardon et al. 2012).

\section{Urbanization}

Urbanization has advanced to the point where rural-urban food supply chains dominate food markets in Asia and Africa. The impacts of urban markets have transmitted deeper and deeper into rural areas, and value chains have grown longer, spurred by urbanization and aided by the spread of rural wholesale markets, rural roads, and rural electrical grids. The rapid urbanization under way in developing regions, especially in Africa and Asia, is discussed in detail in Chapter 9 of this volume. Here we simply add the point that urban population shares underestimate the share of urban areas in total food consumption and total food purchased. This is because urban incomes sufficiently exceed rural incomes, which compensates for the higher-income urban consumers (per Engel's Law [1857]) having lower shares of food in their total budgets. ${ }^{1}$ In Eastern and Southern Africa, 25 percent of the population is urban, but cities consume 48 percent of food produced and sold in the countries. In Asia, Reardon, Hu et al. (2015) show that while 38 percent of the population is urban, 53 percent of the (purchased) food market is urban.

\section{Diet Change}

Whereas Chapter 10 in this volume focuses on nutrition, agriculture, and health linkages, this chapter emphasizes changes in diets in developing regions that have important effects on the transformation of value chains per se. Diets have gone from (traditionally) mainly home-produced to increasingly purchased. Even the rural poor are heavily engaged in the food market as buyers. In the developing countries of Eastern and Southern Africa, for example, Dolislager, Tschirley, and Reardon (2015) show that rural households bought 44 percent (in value terms) of food they consume. Reardon, Hu et al. (2015) show that in Nepal, Indonesia, and Viet Nam, rural households bought 73 percent of their food (in value terms).

1 Engel's Law states that as incomes increase, the share of those incomes that is spent on food decreases. 
There has been substantial diet diversification into processed food with penetration first in urban but also in rural areas. In Eastern and Southern Africa (Tschirley et al. 2015) urban households dedicate 56 percent of food expenditures to processed foods, and rural households, 29 percent. In Asia (Reardon, Hu et al. 2015) urban households dedicate 73 percent of food expenditures to processed foods, and rural areas, 60 percent. In addition, there has been much diet diversification beyond grains, with only modest differences between urban and rural. In the Eastern and Southern Africa study countries, the share of nongrains in urban food expenditure was 66 percent, and rural, 61 percent. In Asia the figures were 74 percent for urban and 63 percent for rural.

The middle class at least in Asia and Latin America has increasing demand for food quality and safety, in particular for semiprocessed foods such as dairy and to a certain extent for perishable foods (Ortega et al. 2012; Pingali 2006). Diets remain basically local-with only a small share imported. For example, 80 percent to 90 percent of national food consumption is supplied by domestic supply chains. Based on our calculations from FAOSTAT food balance sheets and COMTRADE, imports are only 10 percent to 20 percent (in 2010 for Eastern and Southern Africa, 15 percent; West Africa, 11 percent; South Asia, 10 percent; and Southeast Asia, 21 percent).

There have been several drivers of diet change in developing regions. Diet change is driven by factors on the demand side. Income increase drives a relative shift toward nonstaples (per Bennett's Law). But that income increase is not only between poor and middle-class status: Dolislager, Tschirley, and Reardon (2015) show for Eastern and Southern Africa that sharp changes in diet occur over the segments of the poor, with the rate of change steeper than between the poor and nonpoor segments. With urbanization, women are increasingly working outside the home, and thus with rising opportunity costs of time to shop for, process, and prepare food. Men are increasingly working far from home. These trends spur purchase of "convenience cereals" like rice and wheat (Senauer, Sahn, and Alderman 1986) as well processed foods and restaurant-prepared foods.

Diet change has also been driven by factors on the supply side. The food processing sector has grown fast over the past several decades. Agriculture has rapidly diversified beyond grains into horticulture, dairy, livestock, fish, and pulses. Rural-urban food supply chains have developed enormously to move these products to urban as well as rural consumers; Reardon, Tschirley et al. (2015) calculated that African food supply chain volumes increased 
six- to eight-fold over 1970 to 2010 , with most of the increase in the past 20 years.

\section{Trends in Transformation of the Downstream and Midstream of Food Value Chains}

Changes in the structure and conduct of FVCs have occurred over the whole length of the chain as a system, as well as at the level of each segment-from downstream, to midstream, to upstream.

\section{Overall Changes in Food Value Chains}

Urbanization and better transport infrastructure have induced spatial lengthening and deseasonalization of FVCs, to draw from an increasingly broad market-catchment area to feed cities. There has been a proliferation of traditional intermediaries and then a reduction of their numbers and a rise of modern intermediaries. Traditionally there was a short FVC (from farms to the local villages and towns). With urbanization, however, the FVCs grew longer, and there was a proliferation of rural brokers and wholesalers, urban wholesalers, urban semiwholesalers, transporters, warehouse firms, and retailers, all as small-scale firms. As consolidation in processing and retail occurred, there has been a shift, fastest in processed and semiprocessed foods, slowest in perishables, toward the exit (or absorption) of small rural brokers and small processors (Reardon 2015). With the rise of supermarkets and processors, there is also a "re-intermediation" with the rise of dedicated/specialized wholesalers (Reardon and Berdegué 2002).

In links between FVC segments, there is organizational and institutional change, albeit at very different paces depending on the product, the scale of the firm buying the product, and the country. There is a start of vertical coordination through de facto semicontractual relations, like supplier lists (Berdegué et al. 2005), and some formal (even if just verbal) contracts. The latter are still limited but the former appears to be spreading especially among large companies. There is a rise of private standards (Reardon et al. 1999) specified in the contracts. Moreover, a traditional method of intersegment linkage, tied output-credit markets (Bardhan 1980), where a trader advances funds to a farmer and then expects his harvest at the end of the season, have declined substantially. This has been shown in Asia for rice and potato sectors (Reardon et al. 2014) and Africa generally (Adjognon, Liverpool-Tasie, and Reardon 2017). 


\section{Waves of Diffusion of Downstream and Midstream Transformation}

\section{OVERVIEW OF WAVES OF DIFFUSION}

Despite heterogeneous conditions, there is some regularity in waves of diffusion, over countries and within countries, over income classes, and over products. The first wave was in countries that started their post-World War II growth spurt, urbanized, and started industrializing earlier-in particular, South American countries, East Asia outside of China, and South Africa. The start of processing transformation occurred with FDI liberalization and the start of privatization in the mid-1980s to early 1990s. Retail transformation took off from the early 1990 s.

The second wave was in countries that had their growth and urbanization spurts later and/or had prolonged internal sociopolitical pressure to limit FDI. In Central America, Mexico, and Southeast Asia, processing transformation took off in the 1980 s, but retail transformation did not start until the mid to late 1990s. The third wave was in countries, such as in China, India, and Viet Nam, that had their growth and urbanization spurts mainly in the 1990 s and 2000s and/or had lagged liberalization into the 1990s. Processing transformation occurred somewhat before retail, with the latter mainly in the late 1990s and the 2000s. There was also a late part of the third wave, or a fourth wave, an incipience of processing and retail transformation in East and Southern Africa.

\section{THE DOWNSTREAM SEGMENT TRANSFORMATION: RETAIL}

The retail segment has changed as the result of direct government action as well as by the relinquishing of government involvement and the rapid diffusion of private-sector supermarkets. The modern retailers themselves had several phases of change in their conduct-in particular the shift from traditional to modern procurement systems. There were several changes, as follows.

First, governments themselves induced directly a first stage of retail transformation from traditional, fragmented retail to state-run chain storesprior to liberalization and privatization in the 1990s and 2000s, when most of the state chains were dismantled. Examples are the Fair Price Shops in India. Second, after the liberalization of retail FDI and privatization of state retail, there was a huge surge in the 1990s and 2000s in private investment in supermarket chains in developing countries (Reardon et al. 2003). The waves of diffusion emerged in the spatial pattern discussed earlier. The share of modern retail in overall food differs over the wave of diffusion, with the 
deepest penetration to date in the first-wave countries, where the share is near half by the late 1990 s and 50 percent to 60 percent in the 2000s; in the second-wave countries, about 30 percent to 50 percent by the 2000 s; and in the third-wave countries, some 10 percent to 30 percent. The fastest spread is in the third-wave countries in Asia, where the supermarket sector is growing at three to five times the rate of GDP per capita growth (Reardon et al. 2012).

Third, inside a country, diffusion has rolled out from large cities to small cities and finally into rural towns in adapted formats, from upper to middle to poorer classes, as well as from processed foods to semiprocessed foods to fresh produce. These paths are essentially the same as occurred in the United States and western Europe. Fourth, to become cost-competitive with traditional retail, supermarket chains have increasingly modernized their procurement systems. They have started to buy direct from processors including under contracts; (in some cases) specify private standards; use centralized procurement and logistics via distribution centers; and use specialized-dedicated wholesalers who distribute to their stores and also organize procurement from suppliers according to volume and quality and timing specifications (Reardon and Berdegué 2002). This has gone by far the furthest in processed foods but has started to be applied to fresh produce as well (see, for example, Berdegué et al. 2005 for Central America).

\section{THE MIDSTREAM SEGMENT TRANSFORMATION: PROCESSING}

Similar and in parallel to the retail sector, the processing sector has transformed in structure and conduct. The processed food sector has grown quickly over the past several decades. Packaged food sales are growing at only 2 percent to 3 percent annually in developed countries, versus 13 percent, 28 percent, and 7 percent in low, lower-middle, and upper-middle income developing countries (Wilkinson and Rocha 2009). As in retail and wholesale, the first stage of transformation of food processing was driven mainly by governments setting up parastatals, especially in grains (and in export crops like rubber). However, the actual effect on food systems was limited, as the parastatal processors were mainly confined to grain sold to urban markets while there were large "parallel markets" (not via parastatals). In addition, there was rapid privatization in the late 1980s or 1990s. Only a few countries still have substantial government food processing operations into the 2000s.

Privatization and liberalization combined with urbanization, and income increase led to two phenomena that we referred to as the $\mathrm{J}$-curve. On the one 
hand, especially in the 1990s through the present, there was a proliferation of small and medium-sized enterprises (SMEs) in the processing of grain, dairy, meat, fish, and produce both to fill the gap left by the demise of public-sector operations and to meet growing urban demand. This is the transitional stage of FVC transformation. Examples include teff in Ethiopia (discussed below); dairy, wheat, and horticultural product processing SMEs in Brazil (Farina 1997; Farina et al. 2005); and maize, vegetable, and fruit processing in Africa (Broutin and Bricas 2006; Jaffee and Morton 1995; Rubey 1995; Tschirley et al. 2015).

On the other hand, privatization and FDI liberalization led to an avalanche of FDI from western Europe and the United States, then from Japan. The consequence was that foreign firms formed a major share of the processing sector in a number of first- and second-wave countries by the end of the 1990s, and the trend has started in third- and even fourth-wave countries in the 2000s. Regional multinationals like CP (Thailand) and Bimbo (Mexico) are also buying domestic processors in their regions in the $2000 \mathrm{~s}$ (Wilkinson and Rocha 2009). This is starting in Africa, such as the 2015 purchase of Blue Ribbon (a large maize mill in Zimbabwe) by Bakhresa (a large wheat and maize mill in Tanzania) or the acquisitions by Olam International (a large agribusiness group started in Nigeria) of several mills in West Africa. Large regional multinationals have acquired large US and European processors; an example is the 2014 acquisition by Shuanghui (China) of Smithfield Foods (United States), which had been the largest pork processor in the world (Zhang, Rao, and Wang 2019).

This latter part of the $\mathbf{J}$-curve is the modernization stage where consolidation is occurring. For example, by the early 2000s, Nestlé had a 61 percent market share in Latin America for packaged foods (confections, soups, pet food, baby food, dairy, and baked goods). This has been driven by large processing firms' having advantages in processing compared to small and medium-sized enterprises. Larger processors often have economies of scale; economies of scope; bargaining power, monitoring capacity, and "resource provision contract" capacity; access to cheaper credit; as well as more efficient marketing systems, such as via the use of distribution centers and logistics fleets. This has created a symbiosis between large-scale processors and supermarket chains.

In the modern stage, SMEs have found it hard, especially in the medium term, to compete with large processors. Examples are large tortilla firms displacing traditional women's tortilla firms in Mexico (Rello and Saavedra 2007). The emerging penetration of rural towns by modern retail, selling 
branded processed foods at a discount, may accelerate this competition (Reardon, Henson, and Berdegué 2007). With health crises, consumers have also moved away from small processors and wet markets as a result of food safety concerns (for Thailand, see Posri and Chadbunchachai 2006).

\section{THE MIDSTREAM SEGMENT TRANSFORMATION:}

\section{WHOLESALE AND LOGISTICS}

While governments played a major role in the development and transformation of wholesale markets, the overall segment of wholesale and logistics underwent changes similar to that of processing, with an expansion, fragmentation following liberalization and privatization, and then concentration. We note these changes as follows. Governments induced directly a first stage of wholesale transformation from traditional, fragmented wholesale to government-run wholesale markets (of private wholesalers). This shift created economies of agglomeration and sometimes economies of scale relative to the traditional fragmented wholesale sector, such as in Africa (Tollens 1997). The large markets created by this investment are huge, such as that in Mexico City, the world's largest wholesale market. China's wholesale market volume increased 11,000 percent from 1990 to 2000 (Ahmadi-Esfahani and Locke 1998; Huang et al. 2007).

The "traditional" wholesale sector appears to be restructuring in several ways. First, the public-sector wholesale market segment is consolidating in some countries, over wholesale markets, such as South Africa (Louw et al. 2007), and over wholesalers within wholesale markets, such as in Mexico (Echánove and Reardon 2006) and Peru (Escobal and Agreda 1997). There is also in some countries evidence of a decline in the share of rural brokers upstream in the FVC, with the exit of village traders in Bangladesh, India, and China in rice and potato (Reardon et al. 2012). But in the segment from rural towns to cities, it appears that SMEs in wholesale and logistics are proliferating. Reardon et al. (2012) call this proliferation a "quiet revolution in food supply chains" that is being observed in Asia and increasingly in Africa (Reardon, Tschirley et al. 2015; Minten, Tamru et al. 2016).

Beyond the traditional wholesale sector, a modern wholesale sector is emerging, with the emergence of the specialized/dedicated modern wholesalers noted earlier, as well as large-scale foreign and domestic logistics firms. In some cases large processors and retailers are buying direct from suppliers, most commonly with respect to procurement from processors (such as Carrefour buying from Nestlé). 


\section{Local Confluences of Transformation of Food Value Chains: Two Examples}

\section{Cold Storages in Agra, India}

The technology shift in the midstream can be rapid and dramatic, in particular when it is linked to increasing urban demand, improving infrastructure, and a policy of encouragement and support. The case of the rapid rise of potato cold storages in South Asia illustrates this-for example, in Bangladesh (Reardon et al. 2012), in Bihar (Minten, Reardon et al. 2014), and in western Uttar Pradesh near Delhi (Das Gupta et al. 2010). We focus on the last.

A survey of cold storages in Agra found a combination of the following factors to have caused the diffusion of cold storages: (1) the rapid development of vegetable demand in Delhi; (2) the improvement of the road link from Agra to Delhi; (3) the introduction of a disease-resistant and long-shelf-life potato variety; (4) the introduction of an electricity grid; (5) the partial subsidizing of irrigation pumps and cold storage equipment; and (6) the economy's generating investable funds among the intermediate city business sector. These changes drove rapid diffusion of modern cold storages and, in turn, a reduction in the seasonality and cost of potatoes in Delhi as well as shifts in the intermediation patterns in the rural areas.

In the early 1990s relatively few farmers grew potatoes in Agra and there were almost no modern cold storages. By the late 1990s, however, cold storages had risen to store 40 percent of the vastly larger potato output, and by 2009 , 80 percent. Traditional on-farm storage went from ubiquitous to just 1 percent of the potato harvest. Delhi went from sharply seasonal potato consumption (from fresh harvest) to multiseason availability and 65 percent of consumption from cold-storage potatoes, mainly from Agra. Rural brokers were sidelined by the cold storages themselves becoming the main locus of intermediation, with urban wholesalers coming (despite formal regulations barring this) to buy potatoes from farmers at the storages.

\section{Teff Supply Chain to Addis Ababa, Ethiopia}

Teff is the leading cereal in Ethiopia. The marketed surplus of teff to domestic markets in 2013/2014 was $\$ 750$ million, higher than that of coffee (\$560 million), the most important Ethiopian export product. An explosion of growth in the teff value chain to Addis Ababa has occurred over the past decade, based on field surveys of farmers, rural and urban wholesalers, and truckers midstream, as well as field surveys of cereal retail shops, mills, and co-op retailers downstream (Minten, Tamru et al. 2016). 
Addis has experienced a proliferation of SME mills-cum-retailers and rapid transformation all along the supply chain. The recent development of the teff value chain was found to be driven overall by the following: (1) significant growth in Addis and increase in incomes (with a doubling of income and a doubling of teff expenditure since the beginning of the 2000s); (2) increased opportunity cost of women's time (saving time cleaning and milling teff and making enjera [teff pancake]); (3) the diffusion of cell phones; (4) improvements in roads and reduction of transport costs; and (5) the provision of teff government extension services.

The development of the teff value chain was in turn correlated with the following: (1) increasing adoption of modern inputs (chemical fertilizers, improved varieties of seed, and herbicides) by farmers, especially by those living close to urban centers; (2) rising quality demands and important shifts from the cheap red varieties to the more expensive white teff varieties, with concomitant increases in productivity due to the uptake of improved varieties; (3) increasing consumer willingness to pay for convenience in urban areas, with the rapid emergence of one-stop retail shops that provide sales, cleaning, milling, and transport services as well as a sizable food service industry; and (4) declining share of the margins of rural-urban marketing, urban distribution, and milling in the final retail prices of teff, indicating improved marketing efficiency over time.

Traditionally, and still in rural areas and small cities and towns outside of Addis, consumers buy teff as a grain, clean it at home, have it custom-milled, and then prepare enjera at home. These practices have changed in Addis since the beginning of the 2000s, with a decline in custom milling and in cleaning grain at home. Instead, consumers are buying teff flour or enjera, driving a sharp increase (nearly 50 percent) of teff mills, enjera-making enterprises, and retail outlets in the neighborhoods.

Moreover, the wholesale marketing of teff has surged. This segment is seldom studied, as attention is usually paid only to the farm segment. Minten, Tamiru, and Stifel (2014) show that cereal wholesale market activity-including teff and other cereals, such as maize and sorghum—has recently been developing quickly. Focus group participants in a wholesale market survey in Ethiopia were asked about levels and trends concerning the numbers of traders and brokers in the markets as well as cereal trucks arriving in these markets. The reported numbers confirm that the marketed surplus of teff had increased rapidly over the past decade, and significantly more trade was reported on average in these markets over time. The reported number of trucks increased over the decade by almost 70 percent and 80 percent in the peak and lean periods, respectively. 
These teff value chain growth rates are faster than the urban population growth rates in Ethiopia, indicating higher consumption levels in the cities over time, more trade between rural areas that might pass through these urban wholesale markets, and shifts from other means of transportation to trucks. There was a rapid shift from transport of teff by foot (head loads) to animal transport (donkey/horses, carts), to motorized transport, and then from small trucks of 4 to 5 tons to truck-trailers of 20 tons-a rapid transport change in a decade.

\section{The Waves of the Research Literature on FVCs}

The literature on value chains has developed in three waves since 1950, largely reflecting the real-world development of FVCs and the stages of the product cycle discussed earlier in this chapter.

\section{First-Wave Literature: Food Supply Chains in the Commoditization Phase and Transitional Stage}

\section{TRENDS LEADING TO THE EMERGENCE OF THE FIRST WAVE}

Developing regions in the 1980 s through the 2010s were undergoing the following rapid changes: (1) urbanization; (2) shifting diets from graindominated to diversified diets with substantial consumption of nongrains (meat, fish, dairy, horticulture products, edible oils); (3) lengthening supply chains; (4) shifting from local niche to commodity products (and in some cases beyond that in the product cycle, into differentiated products adding variety and quality); and (5) shifting from home-grown and purchasedunprocessed products to relying on purchased food, including a substantial amount of processed products (as women took jobs outside the home).

Yet these very same trends and processes occurred in the United States (and western Europe) from the 1920s through the 1980s (Barkema, Drabenstott, and Welch 1991). The United States went from a traditional food system - with a low share of urbanization, grain-focused diets, bare emergence of purchased-processed food-in the 1920s to a food system that fits closely our description of a "transitional" food system by the 1950s (with the main part of the shift to modern food systems after 1950 through the 1980s). The urban share of the population was dominant by the 1950 s, as diets had diversified into processed foods and meat as well as some commodity vegetables. Supply chains were increasing in length, becoming national instead 
of local. Large processors and supermarket chains had made their appearance, albeit still with a minority share of the food system.

The genesis of the first strand of FVC literature reflected researchers wrestling with economic and societal issues emerging with what seemed then as a rapid shift to the transitional stage of FVCs and the commoditization phase of the product cycle by the 1950s and the 1960s. But this first wave of literature continued and expanded with application in developing regions starting mainly in the 1980s and beyond, as those regions entered a similar stage.

\section{First-Wave Literature: Meso Analysis of Supply Chains in the Commoditization Phase}

The first wave of food value chain literature (which we call the "food supply chain strand") emerged in the 1950s and 1960s along with the transformation of the FVC in the United States and Europe from the traditional to the transitional stage and the emergence of the modern stage. The founder of this strand can be said to be Ray Goldberg of Harvard Business School, who coined the term "agribusiness systems" for food chains from seed to farm to consumer. Goldberg studied the formation of marketing margins and the use of coordination mechanisms such as contracts and vertical integration along the chain (Davis and Goldberg 1957; Goldberg 1965). Many agricultural economics studies ensued from this approach. Terms used by this strand of studies, with some modest differences of emphasis and method among them, include agribusiness commodity systems; food or commodity chains; filieres; food supply chains; subsectors; and netchains. See, for example, Holtzman (1986); Lazzarini, Chaddad, and Cook (2001); Loader (1997); Raikes, FriisJensen, and Ponte (2000); and, for Africa, Jaffee et al. (2003).

The essence of nearly all the applied studies of this first strand were laid out in the ideas in the work of Goldberg in the 1950s and 1960s, which we summarize here. Goldberg took the basic "vertical chain" idea from earlier literature (such as the input-output literature of the 1930s), married it with the industrial organization literature's "structure-conduct-performance paradigm" discussed earlier, and applied the resulting framework to the rapidly emerging and commoditizing FVCs of that era. Goldberg and others in this first wave incorporated concepts from the growing work in economics (for example, Williamson 1979, 1981) on what were later termed by the NIE (new institutional economics) school as "institutional arrangements"-use of quality and safety standards, use of contracts (such as contract farming, discussed in Chapter 11), use of spot markets versus use of vertical coordination and 
integration, and other "chain coordination" arrangements. As supply chains developed, these institutional arrangements to coordinate them arose, and that reality penetrated the research literature. While Gereffi (1999) and others formalized the ideas in later work (in the value chain strand), Goldberg and others had researched the roles of different segments and lead companies in setting and enforcing coordination arrangements, and studied the role of regulations and policies.

The first wave focused on the burning issues of debate of the day, in the 1960s through the 1980s in the United States and in the 1980s on in developing regions. Questions naturally arise when supply chains shift from traditional to transitional system, in particular:

1. What are the paths and determinants of the proliferation of long FVCs operated by SMEs (in the transitional phase) and emerging large enterprises (in the initial steps of the modern phase)?

2. What are the constraints or bottlenecks faced in the development of commodity FVCs? A key part of this work was to measure marketing costs between segments-later termed "transaction costs" and built on by the NIE school (arising in the 1970s and 1980s, discussed more below).

3. Where are there "excessive" margins indicating noncompetitive behavior such as collusion in price-setting?

4. What is the path and the impact on FVCs of the emerging coordination mechanisms, the new private "institutions"?

Work on these issues brought to bear analysis of structure, conduct, and performance; the impacts of urbanization, developing road infrastructure, and changing diets; and the impacts of domestic and international policies and regulations (on competition, on taxes and subsidies, on marketing orders). At the risk of oversimplifying and ignoring exceptions, the analysis in this wave tended (and tends) to be at the "meso" level, using aggregated data at the segment and zone level, such as the PAM (Policy Analysis Matrix) work (Monke and Pearson 1989), and other supply chain "mapping" analysis. This can be compared with work in the second strand that tended to make more use of business management case studies.

Several recent strands of literature in the first wave have emerged in developing regions. Some descriptive studies have focused on the characteristics of the transitional stage of FVCs in developing countries, emphasizing the 
proliferation of a multiplicity of types of SMEs in the midstream of supply chains as supply chains grew longer. They point to the emergence of large wholesalers based in secondary cities, of third-party logistics enterprises linking urban markets to rural traders and farmers, and to clusters of SME processors. These studies emphasize that there is dynamism in transitional supply chains that is not associated either with large firms or formal contracts or global markets, but rather small firms, informal relations, and domestic urban markets. Examples include Minten, Tamru et al. (2016) for Ethiopia, Verhofstadt and Maertens (2013) for Rwanda, and Reardon et al. (2012) for Bangladesh, China, and India.

Other analytical studies examine the competitiveness of FVCs as agrifood markets and the determinants of trader margins and efficiency. Dillon and Dambro (2017) reviewed African studies on trader competitiveness and found that the segment of traders has efficient levels of competitive arbitrage, as entry and exit rates are high, there is co-movement of prices among markets, and trader margins are highly variable. A small number of studies used trader survey data. For example, Minten and Kyle (1999), for the Democratic Republic of the Congo, examined the determinants of trader margins as a function of transportation costs. They found that these costs, conditioned by road quality, explained food prices between farming regions, and that trader profit rates are higher on poorer roads. Fafchamps, Gabre-Madhin, and Minten (2005) found for Benin, Madagascar, and Malawi, in analyzing margins, costs, and value-added, that there are no significant increasing returns to scale among traders. From this they note the implication that policies to restrict entry into agricultural trade are not needed or useful, and governments should focus on technological and institutional innovations to upgrade markets. By contrast, for shrimp traders in Indonesia, Yi and Reardon (2015) find that larger traders have a cost advantage over small traders and are more efficient in allocating factors. They suggest that this is a possible explanation for the observed concentration occurring over time in the shrimp trader segment.

Other analytical studies examine the participation of small farmers in FVCs in the transitional stage (that is, not sales to modern enterprises or contract relations). An example is Bellemare and Barrett (2006), which analyzed the determinants, among which were transaction costs, of small pastoralists' decisions among autarchy or net sale or net purchase of animals in livestock markets in Ethiopia and Kenya. Barrett (2008) and Holloway et al. (2004) analyzed farmer participation in traditional and transitional grain and milk FVCs, controlling for threshold levels of assets (and thus the possibility of 
"poverty traps") keeping farmers out of markets, and controlling for farmer characteristics, studying the impacts of various shocks to the market (like drought and policies such as devaluation).

\section{Second-Wave Literature: Meso and Business Strategy Analysis in the Product Differentiation Phase of the Product Cycle and Modern Stage of the FVC}

\section{TRENDS LEADING TO THE EMERGENCE OF THE SECOND WAVE}

Three trends in the 1980s through the 1990s in developed countries and mainly the 1990s and beyond in developing countries drove the emergence of this second wave. We briefly summarize these trends:

1. Globalization of food trade and FDI, mainly in retail and processing and logistics from developed to developing regions occurred mainly from the 1980s through to the present.

2. Diets changed rapidly in the developing regions mainly from the 1980s through to the present, with diversification beyond foodgrains, increases in processed food consumption, and food purchases rising among rural households. There was a rise in demand for quality and safety of food.

3. With urbanization and globalization, there was an increase in the length of FVCs, and the shift into trade and internal commerce in products beyond bulk commodity grains and into perishables, and a large variety of processed products drove the implementation by food industry firms of coordination "institutions" ranging from contracts to private standards of quality and safety (Swinnen et al. 2015). These institutions were more widespread and complex than those studied in the first strand during the commoditization phase. The innovations mainly established in developed countries then transferred to developing countries in the 1990s via FDI and other means, thus "fast tracking" transformation of FVCs in developing countries (Reardon, Henson, and Berdegué 2007; Reardon et al. 2019).

Another factor besides competition and developed-developing country transfer of investments and techniques drove the jump from commodity supply chains to differentiated and coordinated value chains. Intra-developed country rivalry and transfer of techniques also spurred the process. A wellknown example is the drive in Japan for quality differentiation and quality 
assurance (to shed the image and standing of a commodity manufacturer) in the 1960s. They pioneered techniques like total quality management. These were taken up by US manufacturers in the 1970s and the 1980s (Lillrank 1995) and studied by Michael Porter at Harvard Business School. Porter championed "competitive advantage" and the use of quality differentiation and assurance to move beyond the low margin and highly contested commodity markets. Porter was the founder of the second strand of FVC literature, discussed next.

\section{Second-Wave Literature: Meso and Firm Analysis of Value Chains in the Differentiated Product and Modernization Stages}

The second strand of FVC literature, often termed "food value chain governance" literature, emerged in the 1980s and 1990s along with globalization, with the transformation of the FVC in the United States and Europe from the transitional to the modern stage and with the shift along the product cycle from the commodity to the differentiated product stage. The latter was associated in the literature with "adding value" beyond commodity traits (mainly cost), and thus the "value" in value chain was introduced.

An important point is that while both the first and second waves can be said to have been started by two Harvard Business School professors, both in business management, the first wave tended to focus more on the structure and conduct of the whole supply chain, and on cost and efficiency, while the second strand, started by Porter (1985) has tended to focus on business management of quality differentiation and assurance, and by extension strategies of supply chain design by "lead" or "innovator" firms in the supply chain. These emphases were driven by the trends noted earlier in quality differentiation and food industry consolidation and competition. This wave of literature started to become important in developing regions starting in the 1990s and 2000 s with the rise of large processors, supermarkets, and private standards and in general with the start of modernization in FVCs.

The second wave has two main strands. A first strand focuses on the institutions of "governance" present in FVCs. Kaplinsky and Morris (2000) inventory the following types of governance: (1) legislative governance (setting the rules such as standards for cost, quality, and volume); (2) judicial governance (monitoring compliance with requirements); and (3) executive governance (either sanctioning suppliers that do not meet the standards, or assisting suppliers, such as small farmers, to be able to meet the requirements). An example is "resource providing contracts" that provide credit and technical assistance to small farmers (Austin [1981] and Kuijpers and Swinnen [2016] in general, 
and, for cases in Slovakia and Poland, Gow and Swinnen [1998] and Dries and Swinnen [2004]).

Part of this first strand is analysis of private standards. That theme had been present in earlier work (such as Goldberg's [1968] work on industry standards for orange juice in the United States). But the global food industry greatly increased its use of private standards in the 1970s and 1980s in developed as well as developing countries for the portion of the food economy in interface with the world market as well as large food processors and supermarket chains focused on the domestic market (Reardon et al. 1999; Fulponi 2006; Swinnen 2007).

A second strand of this second wave analyzes the strategies of design choices made by businesses to gain and protect and build competitive advantage. Porter (1985) focused on this issue using case studies of firms choosing what and how to design and market a quality-differentiated product. The main choices concerned product traits, marketing strategies, and coordination mechanisms. Addressing a similar issue to that of Porter's work is that of Zilberman, Lu, and Reardon (2019), using economic models to examine the strategic choices of "innovator" businesses in terms of the design of value chains that will allow the innovator to create or capture a market for the innovation (product, technology, or application) and protect a competitive advantage. The work is integrative in comparison to earlier economic analyses that focused on specific aspects of value chain relations, such as transaction cost theory (Hobbs 1997) or contract theory (Goodhue 2011; Bolton and Dewatripont 2005).

Zilberman, Lu, and Reardon (2019) note that an innovator-cumentrepreneur makes an integrated set of choices to implement the innovation in a supply chain. These include the following:

1. How much to produce of the product, given capital constraints.

2. Looking upstream, whether and how much a firm should grow its own intermediate input or buy it from farmers or other suppliers; looking downstream, whether and how much a firm should produce its own marketing services for processed output.

3. If the innovating processor decides to buy intermediate inputs (such as paddy for a rice mill) from farmers (or buy marketing services from distribution firms), whether to contract with the farmers (or distribution firms) or buy the intermediate input (or services) from them in a spot arrangement. 
4. If the innovator, such as a processor, decides to grow its own intermediate input or marketing services, what technology to use.

5. If the innovator decides to contract, what design (terms) the contract should have.

6. The degree of monopsony and monopoly, as well as government regulation, change or condition the answers to the first five choices.

In the 1990s, as global FVCs formed and domestic and international chains stretched long and included actors of unequal economic power (such as vegetable farmers in Kenya selling to UK supermarkets), there arose a strand of literature focusing on the distribution of "rents" over segments of international chains. This was extended to domestic supply chains in developing countries in the 2000s. Here, a "rent" is a payment to an owned factor beyond the payment that would accrue under perfect competition (where the factor price is equated with the marginal value product from a unit of that factor). Although this arose as a "new" literature, it was in essence similar to the supply chain analyses of the 1960s in the United States that tested whether a given segment had monopoly or monopsony power arising from noncompetitive practices, looking for super-profits along the chain.

Such rents can be of different kinds, according to Kaplinsky and Morris (2000), including the following: (1) economic rents from differential productivity of factors plus barriers to entry (attained by exercise of market power); (2) technology rents, where the firm has command over scarce or innovative technologies; (3) human resource (skills) rents; (4) organizational rents (derived from internal organization of the firm, such as ability to combine economies of scale in procurement with close contact with clients in many markets, through chain store location, or from external organization, such as a farmers' cooperative or a buyers' club); (5) marketing rents (derived from marketing skills and organization but also from brands); (6) relational rents (derived from preferential relations with suppliers, such as in contract farming schemes or various "lock-in" arrangements, or with clients which in turn might be due to brands required by the buyer, such as a retailer, or payment of slotting fees [for example, for packaged rice or potato chips] or both); (7) resource (and we would add, infrastructural/locational) rents; (8) policy rents; and (9) financial rents (derived from better access to finance, which in turn might be derived from being in the formal sector, being near infrastructure, and other factors linked to other rents). 
Rents can be correlated with "power" of the chain actor to ensure consequences along the chain (such as meeting of standards by suppliers) and to actively coordinate links (such as imposing standards via contracts and enforcing contracts with sanctions). This power typically emerges from an ability to set up barriers to competition (through some unique advantage that also generates rents) and derives from segment concentration. That power is sometimes vested in a "lead firm" or set of firms who set the rules (but are not necessarily the ones to implement and monitor the application of the rules by suppliers) (Swinnen et al. 2015). The lead firm may also issue contracts to resolve uncertainty of suppliers that impedes the needed investments to meet private standards and adopt requisite technologies, such as in the pork industry in the United States (Maples, Lusk, and Peel 2019).

Gereffi (1999) distinguished FVCs by the position in the chain of the lead firm (with "lead" conflated with "power" in the chain): (1) "buyer-driven FVCs" (such as the UK supermarket-driven chain sourcing from Kenya, described in Dolan and Humphrey [2000]); or (2) "supplier driven FVCs" where, say, a producers' organization sets the rules. The rise of the power of food industry firms due to concentration and their advantages drawn from branding and marketing have meant that buyer-driven FVCs have proliferated and supplier-driven FVCs have declined over the past several decades.

There is an emerging literature that combines lead-firm strategies and analysis of distributional impacts of these strategies. An example is the impacts of quality and sustainability certification in the coffee value chain. Minten et al. (2018) examine the distribution over segments in the coffee value chain in Ethiopia of the quality premium of certified coffee. To study the whole value chain, they combined datasets of small farmers, larger commercial coffee farms, cooperatives and traders, and coffee export transactions. They analyzed the impacts of certification of voluntary sustainability standards (VSS), in particular Fair Trade and Organic certifications, which are rapidly increasing in global value chains. They found that the transmission of export quality premiums to coffee producers is limited, with only less than a third of the premium passed on to farmers and totaling very little relative to farmers' overall incomes. Similar results of constraints to the benefits of certification were found in the coffee sector in Guatemala by de Janvry, McIntosh, and Sadoulet (2015).

\section{Third-Wave Literature: The Microeconomics of Participation in and Effects of Modernizing and Product-Differentiating FVCs}

This wave is a direct extension from meso to micro of the second wave and thus is motivated by the same trends. The transformation of FVCs from 
traditional to transitional to modern, and along the product cycle, presents opportunities for suppliers in the various segments of the chain. But they also present challenges. These impacts are studied in several strands of literature, emerging in the 1980s and 1990s but really taking off in the 2000s and especially the 2010s, along with the perception (we surmise born largely from the second wave of literature) of the importance and progress of the transformations as well as the confluence of sufficient survey data and econometric and RCT (randomized controlled trial) methods and computational power over the past several decades.

A first strand has used econometrics and farm survey data to study the determinants and impacts of participation in transformed FVCs. The cost and quality requirements implied by private standards as implemented in contracts and other enforcement mechanisms translate into a set of needed investments or "upgrading" measures by suppliers. This strand identifies the upgrading investments and empirically determines what kinds of suppliers can make the grade to participate or be included in the transforming FVC. This is akin to the earlier literature on "threshold investments" for technology adoption, such as during the Green Revolution (Feder, Just, and Zilberman 1985).

In this first strand, there has been a substantial literature on participation in and impacts of contract farming for some 30 years. This literature (114 articles) was critically reviewed as to findings and methods in Bellemare and Bloem (2018). They note that the literature does not conclusively answer whether contract farming improves farmer welfare because few articles are internally and externally valid. That is, the great majority are not rigorously causal, or apply to only a few crops, a particular area, or a single year. They recommend that future research go beyond just asking whether contracts make farmers better off, and explore the mechanisms by which contracts affect farmers, in particular whether and how they resolve market failures. Moreover, they note the importance of exploring further costs and not just the benefits of contract farming. They find there is too little research on the spillover effects of contract farming and recommend more work on spillovers. They note that internal validity, linked to the selection problem, is an important problem in many studies, and that researchers need either to undertake differences-in-differences design or conduct an RCT.

In addition, the contract farming literature has tended to find mixed results concerning whether smaller farmers are less likely to participate in transformed value chains compared with medium or larger farmers. The factor impeding participation at times is the transaction costs implied by farmers being in "hinterland" zones and difficult for buyers to access (Barrett et 
al. 2012). The constraint can also be nonland assets such as irrigation or education (Reardon et al. 2009). An extension of this is to test hypotheses concerning small farmers' entry into particular market channels, such as modern versus traditional FVCs (see, for example, Hernandez et al. 2007 for the case of traditional versus supermarket channels for tomatoes). A common hypothesis is that contract farming participation and/or sales to a large processor or supermarket is determined by farm size (such as in Indonesia by Simmons, Winters, and Patrick [2005] for seed rice and chicken) and by transaction costs faced by the farmer (such as in Peru by Escobal and Cavero [2012] for potatoes).

Furthermore, although much of the econometric literature examines effects on farmer welfare or incomes, some authors have studied other impacts, such as Rao, Brümmer, and Qaim (2012) on production technology and efficiency of vegetable farmers in Kenya of adoption of the supermarket channel. Finally, much of the econometric literature on contract farming and modern market channel participation (the first strand of the third wave) has framed the decision of the small farmer in terms of the price premium or average priced earned, usually relative to special costs incurred to "make the grade." But Michelson, Reardon, and Perez (2012) examined both price averages and price variability comparing small farmers' selling to the traditional market versus to Walmart in Nicaragua. They found that while Walmart's producer price was lower on average, so was its variance, and farmers preferred to sell to Walmart because of the lower risk.

A second, emerging strand is the use of field experiments such as randomized control trials to test for the effect of market channel and/or contract adoption by farmers. This literature is one way to address the internal validity problem noted by Bellemare and Bloem (2016). Two examples of this include the Casaburi and Macchiavello (2015) study of smallholder dairy markets in Kenya, and Saenger, Torero, and Qaim (2014) for such markets in Viet Nam. Other studies have attempted to overcome the challenge of endogeneity (selection bias) noted by Bellemare and Bloem (2018) using instrumental variable estimation. One example is Bellemare (2012), which uses contingent-valuation methods to control for unobserved heterogeneity among households in Madagascar. Indicators of willingness to pay (WTP) for contract farming are used as a vector of instrumental variables for participation in contract farming. Using that approach, Bellemare finds evidence of a positive farm income effect from participation in contract farming. This method allows for the control of factors omitted by other studies, such as subjective perceptions about contract farming and entrepreneurial ability. 
A third, emerging strand is the study of the effects of modern channels such as supermarkets on the prices paid by consumers (compared with prices in traditional markets). An example is Atkin, Faber, and Gonzalez-Navarro (2018). They studied the impact on consumer welfare of the penetration of foreign supermarkets in Mexico. They find that penetration lowers prices (and thus overall cost of living) in particular for lower-income consumers, as well as benefits from new product variety, new store variety, and store amenities, beyond just price alone.

\section{Conclusions and Assessment of Gaps in the Literature}

This chapter laid out a heuristic conceptual framework to examine the structure, conduct, and performance of agrifood value chains from the perspective of stages of value chain transformation and commoditization and differentiation of products in the product cycle. We discussed evidence of trends in these transformations both in developed countries such as the United States and in western Europe as well as in the developing regions of Africa, Asia, and Latin America. We showed rapid transformation of value chains and a march along the product cycle. At each stage there were occasioned various "real world issues" such as those of competition and inclusion or exclusion of small farmers and cost of living for consumers. We showed that the literature on value chains developed in three waves that essentially tracked the actual transformation of the value chains and continuously oriented toward addressing the issues emerging at each stage.

We showed that the waves of literature have been particularly rich in and adapted to studying the meso-level changes in value chains, such as their length and structure, in both the commoditization and product differentiation phases, in the transitional and modernization stages. More recently, and fed by concerns about the welfare and inclusion impacts of the transformations, and armed with better survey data and computational and elicitation techniques than had characterized the literature before, say, the 1990s, the literature turned to the microeconomic determinants and consequences of the transformation. We discussed the econometric achievements of the literature concerning farmer participation determinants and effects as well as impacts on consumers.

That discussion revealed that there has been a relative dearth of surveys of and analysis of the off-farm components of value chains such as traders, logistics enterprises, and processors. It also revealed econometric challenges in 
identifying impacts of the transformations, as well as the recommendations of recent literature to broaden the applications, for more external validity of the tests and use of experimental and econometric methods such as differences-indifferences to improve the internal validity of the tests. The opportunities for and the need to greatly extend empirical work on the dynamics and impacts of value chain transformation stand as an urgent agenda for agricultural market development researchers in the decades to come.

\section{References}

Adjognon, S. G., L.S.O. Liverpool-Tasie, and T. Reardon. 2017. “Agricultural Input Credit in SubSaharan Africa: Telling Myth From Facts." Food Policy 67: 93-105.

Ahmadi-Esfahani, F. Z., and C. G. Locke. 1998. "Wholesale Food Markets with 'Chinese Characteristics." Food Policy 23 (1): 89-103.

Atkin, D., B. Faber, and M. Gonzalez-Navarro. 2018. "Retail Globalization and Household Welfare: Evidence from Mexico." Journal of Political Economy 126 (1): 1-73.

Austin, J. E. 1981. Agroindustrial Project Analysis. Baltimore: Johns Hopkins University Press.

Bardhan, P. K. 1980. "Interlocking Factor Markets and Agrarian Development: A Review of Issues." Oxford Economic Papers 32 (1): 79-98.

Barkema, A., M. Drabenstott, and K. Welch. 1991. “The Quiet Revolution in the U.S. Food Market." Economic Review (Kansas City Federal Reserve Bank) (May-June): 25-41.

Barrett, C. B. 2008. "Smallholder Market Participation: Concepts and Evidence from Eastern and Southern Africa." Food Policy 33: 299-317.

Barrett, C. B., M. E. Bachke, M. F. Bellemare, H. C. Michelson, and S. Narayanan. 2012. "Smallholder Participation in Contract Farming: Comparative Evidence from Five Countries." World Development 40 (4): 715-730.

Bellemare, M. F. 2012. "As You Sow, So Shall You Reap: The Welfare Impacts of Contract Farming." World Development 40 (7): 1418-1434.

Bellemare, M. F., and C. B. Barrett. 2006. "An Ordered Tobit Model of Market Participation: Evidence from Kenya and Ethiopia." American Journal of Agricultural Economics 88 (2): $324-337$.

Bellemare, M. F., and J. R. Bloem. 2018. "Does Contract Farming Improve Welfare? A Review." World Development 112: 259-271.

Bennett, M. K. 1941. "International Contrasts in Food Consumption." Geographical Review 31 (3): 365-376. 
Berdegué, J. A., F. Balsevich, L. Flores, and T. Reardon. 2005. “Central American Supermarkets' Private Standards of Quality and Safety in Procurement of Fresh Fruits and Vegetables." Food Policy 30 (3): 254-269.

Bolton, P., and M. Dewatripont. 2005. Contract Theory. Cambridge, MA: MIT Press.

Broutin, C., and N. Bricas. 2006. Agroalimentaire et Lutte Contre la Pauvreté en Afrique Subsaharienne: Le Rôle des Micro et Petites Enterprises. Paris: Gret.

Casaburi, L., and R. Macchiavello. 2015. "Loyalty, Exit, and Enforcement: Evidence from a Kenya Dairy Cooperative." American Economic Review 105 (5): 286-290.

Cochrane, W. W. 1979. The Development of American Agriculture: A Historical Analysis. Minneapolis: University of Minnesota Press.

COMTRADE. https://comtrade.un.org/.

Das Gupta, S., T. Reardon, B. Minten, and S. Singh. 2010. The Transforming Potato Value Chain in India: From a Commercialized-Agriculture Zone (Agra) to Delhi. Report of Value Chains Component of Asian Development Bank RETA (13th) International Food Policy Research Institute (IFPRI) Project on Policies for Ensuring Food Security in South and Southeast Asia. October.

Davis, J. H., and R. A. Goldberg. 1957. A Concept of Agribusiness. Boston: Division of Research, Graduate School of Business Administration, Harvard University.

de Figueirêdo, H. S., M. P. M. Meuwissen, and A. G. J. M. Oude Lansink. 2014. "Integrating Structure, Conduct and Performance into Value Chain Analysis." Journal on Chain and Network Science 14 (1): 21-30.

de Janvry, A., C. McIntosh, and E. Sadoulet. 2015. "Fair Trade and Free Entry: Can a Disequilibrium Market Serve As a Development Tool?" Review of Economics and Statistics 97 (July): 567-573.

Dillon, B., and C. Dambro. 2017. "How Competitive Are Crop Markets in Sub-Saharan Africa." American Journal of Agricultural Economics 99 (5): 1344-1361.

Dolan, C., and J. Humphrey. 2000. "Governance and Trade in Fresh Vegetables: The Impact of UK Supermarkets on the African Horticulture Industry.” Journal of Development Studies 37 (2): $147-176$.

Dolislager, M. D., D. Tschirley, and T. Reardon. 2015. "Consumption Patterns in Eastern and Southern Africa.” Report to USAID. Michigan State University, Innovation Lab for Food Security Policy, East Lansing, US, May.

Dries, L., and J. Swinnen. 2004. "Foreign Direct Investment, Vertical Integration, and Local Suppliers: Evidence from the Polish Dairy Sector." World Development 32 (9): 1525-1544. 
Echánove, F., and T. Reardon. 2006. "Wholesale Markets, Horticulture Products, and Supermarkets in Mexico." Staff Paper 2006-17, Michigan State University, East Lansing, US, April.

Engel, E. 1857. "Die Productions- und Consumtionsverhältnisse des Königreichs Sachsen.” Zeitschrift des sächsischen Statistischen Bureaus des Innern 8 and 9: 1-54.

Escobal, J., and V. Agreda. 1997. Analisis de la competitividad y la eficiencia en el Mercado mayorista de productos agropecuarios en Lima. Lima, Peru: GRADE.

Escobal, J. A., and D. Cavero. 2012. "Transaction Costs, Institutional Arrangements and Inequality Outcomes: Potato Marketing by Small Producers in Rural Peru." World Development 40 (2): 329-341.

Fafchamps, M., E. Gabre-Madhin, and B. Minten. 2005. "Increasing Returns and Market Efficiency in Agricultural Trade.” Journal of Development Economics 78 (2): 406-442.

FAOSTAT (Food and Agriculture Organization Corporate Statistical Database). www.fao.org/ faostat/en/\#home.

Farina, E. M. M. Q., ed. 1997. Estudos de Caso em Agribusiness, Focalizando as Seguintes Empresas: Moinho Pacifico, Illycaffe, Cocamar, Sadia, Iochpe-Maxion, Norpac. São Paulo: Pioneira.

Farina, E. M. M. Q., G. E. Gutman, P. J. Lavarello, R. Nunes, and T. Reardon. 2005. "Private and Public Milk Standards in Argentina and Brazil." Food Policy 30 (3): 302-315.

Feder, G., R. E. Just, and D. Zilberman. 1985. "Adoption of Agricultural Innovations in Developing Countries: A Survey." Economic Development and Cultural Change 33 (2): 255-298.

Fulponi, L. 2006. "Private Voluntary Standards in the Food System: The Perspective of Major Food Retailers in OECD Countries." Food Policy 31 (1): 1-13.

Gereffi, G. 1999. "International Trade and Industrial Upgrading in the Apparel Commodity Chain." Journal of International Economics 48: 37-70.

Goldberg, R. A. 1965. "Marketing Costs and Margins: Current Use in Agribusiness MarketStructure Analysis." Journal of Farm Economics 47 (5): 1352-1365.

- 1968. Agribusiness Coordination: A Systems Approach to the Wheat, Soybean and Florida Orange Economies. Boston: Division of Research, Graduate School of Business Administration, Harvard University.

Goodhue, R. E. 2011. "Food Quality: The Design of Incentive Contracts." Annual Review of Resource Economics 3: 119-140.

Gow, H. R., and J. Swinnen. 1998. "Up- and Downstream Restructuring, Foreign Direct Investment, and Hold-Up Problems in Agricultural Transition." European Review of Agricultural Economics 25 (3): 331-350. 
Henson, S., and T. Reardon. 2005. "Private Agri-Food Standards: Implications for Food Policy and the Agri-Food System." Food Policy 30 (3): 241-253.

Hernández, R., B. Belton, T. Reardon, C. Hu, X. Zhang, and A. Ahmed. 2018. "The 'Quiet Revolution' in the Aquaculture Value Chain in Bangladesh." Aquaculture 493: 456-468.

Hernández, R., T. Reardon, and J. A. Berdegué. 2007. "Supermarkets, Wholesalers, and Tomato Growers in Guatemala." Agricultural Economics 36 (3): 281-290.

Hobbs, J. E. 1997. “Measuring the Importance of Transaction Costs in Cattle Marketing.” American Journal of Agricultural Economics 79 (4): 1083-1095.

Holloway, G., C. Nicholson, C. Delgado, S. Staal, and S. Ehui. 2004. “A Revised Tobit Procedure for Mitigating Bias in the Presence of Non-Zero Censoring with an Application to Milk-Market Participation in the Ethiopian Highlands." Agricultural Economics 31: 97-106.

Holtzman, J. S. 1986. "Rapid Reconnaissance Guidelines for Agricultural Marketing and Food System Research in Developing Countries." MSU International Development Papers, Working Paper 30. Department of Agricultural Economics, Michigan State University, East Lansing, MI.

Huang, J., X. Dong, Y. Wu, H. Zhi, X. Nui, Z. Huang, and S. Rozelle. 2007. Regoverning Markets: The China Meso-Level Study. Report. Beijing: Center for Chinese Agricultural Policy, Chinese Academy of Sciences, July.

Jaffee, S., R. Kopicki, P. Labaste, and I. Christie. 2003. Modernizing Africa's Agro-Food Systems: Analytical Framework and Implications for Operations. Africa Region Working Paper 44. Washington, DC: World Bank.

Jaffee, S., and J. Morton, eds. 1995. Marketing Africa's High-Value Foods: Comparative Experiences of an Emergent Private Sector. Dubuque, IA: Kendall Hunt.

Kaplinsky, R., and M. Morris. 2000. A Handbook for Value Chain Research. Ottawa: International Development Research Centre.

Kuijpers, R., and J. Swinnen. 2016. "Value Chains and Technology Transfer to Agriculture in Developing and Emerging Economies." American Journal of Agricultural Economics 98 (5): 1403-1418.

Lazzarini, S. L., F. R. Chaddad, and M. L. Cook. 2001. "Integrating Supply Chain and Network Analysis: The Study of Netchains." Journal on Chain and Network Science 1 (1): 7-22.

Lillrank, P. 1995. “The Transfer of Management Innovations from Japan.” Organization Studies 16 (6): 971-989. 
Liverpool-Tasie, S., T. Reardon, A. Sanou, W. Ogunleye, I. Ogunbayo, and B. T. Omonona. 2017. "The Transformation of Value Chains in Africa: Evidence from the First Large Survey of Maize Traders in Nigeria." Nigeria Agricultural Policy Project, Research Paper 91. December. Michigan State University, East Lansing, MI.

Loader, R. 1997. "Assessing Transaction Costs to Describe Supply Chain Relationships in AgriFood Systems." Supply Chain Management: An International Journal 2 (1):23-35.

Louw, A., D. Chikazunga, D. Jordaan, and E. Bienabe. 2007. "Restructuring Food Markets in South Africa: Dynamics in Context of the Tomato Sub Sector.” Meso Report for the Regoverning Markets Program. University of Pretoria, South Africa. May.

Maples, J. G., J. L. Lusk, and D. S. Peel. 2019. “Technology and Evolving Supply Chains in the Beef and Pork Industries." Food Policy 83 (February): 346-354.

Michelson, H., T. Reardon, and F. Perez. 2012. "Small Farmers and Big Retail: Trade-Offs of Supplying Supermarkets in Nicaragua." World Development 40 (2): 342-354.

Minten, B., M. Dereje, E. Engida, and S. Tamru. 2018. "Tracking the Quality Premium of Certified Coffee: Evidence from Ethiopia." World Development 101: 119-132.

Minten, B., and S. Kyle. 1999. "The Effect of Distance and Road Quality on Food Collection, Marketing Margins, and Traders' Wages: Evidence from the Former Zaire." Journal of Development Economics 60 (2): 467-495.

Minten, B., T. Reardon, S. Das Gupta, D. Hu, and K. A. S. Murshid. 2016. "Wastage in Food Value Chains in Developing Countries: Evidence from the Potato Sector in Asia." In Food Security in a Food Abundant World. Frontiers of Economics and Globalization (Book 16), edited by A. Schmitz, P. L. Kennedy, and T. Schmitz, 225-238. Bingley, UK: Emerald Group Publishing.

Minten, B., T. Reardon, K. M. Singh, and R. Sutradhar. 2014. "The New and Changing Roles of Cold Storages in the Potato Supply Chain in Bihar." Economic and Political Weekly, December 27, 98-108.

Minten, B., E. Tamru, E. Engida, and K. Tadesse. 2016. "Feeding Africa's Cities: The Case of the Supply Chain of Teff to Addis Ababa." Economic Development and Cultural Change 64 (2): 265-297.

Minten, B., S. Tamiru, and D. Stifel. 2014. "Structural Transformation in Cereal Markets in Ethiopia." Journal of Development Studies 50 (5): 611-629.

Monke, E. A, and S. R. Pearson. 1989. The Policy Analysis Matrix for Agricultural Development. Ithaca, NY: Cornell University Press.

Nakasone, E., M. Torero, and B. Minten. 2014. “The Power of Information: The ICT Revolution in Agricultural Development." Annual Review of Resource Economics 6: 533-550. 
Ortega, D. L., H. H. Wang, N. J. Olynk, L. Wu, and J. Bai. 2012. "Chinese Consumers' Demand for Food Safety Attributes: A Push for Government and Industry Regulations." American Journal of Agricultural Economics 94 (2): 489-495.

Pingali, P. 2006. "Westernization of Asian Diets and the Transformation of Food Systems: Implications for Research and Policy." Food Policy 32: 281-298.

Porter, M. E. 1985. Competitive Advantage: Creating and Sustaining Superior Performance. New York: Free Press.

Posri, W., and S. Chadbunchachai. 2006. "Consumer Attitudes towards and Willingness to Pay for Pesticide Residue Limit Compliant 'Safe' Vegetables in Northeast Thailand." Journal of International Food \& Agribusiness Marketing 19 (1): 81-101.

Qanti, S. R., T. Reardon, and A. Iswariyadi. 2017. "Triangle of Linkages among Modernising Markets, Sprayer-Traders, and Mango-Farming Intensification in Indonesia." Bulletin of Indonesian Economic Studies 53 (2): 187-208.

Raikes, P., M. Friis-Jensen, and S. Ponte. 2000. "Global Commodity Chain Analysis and the French Filière Approach." Economy and Society 29 (3): 390-417.

Rao, E. J. O., B. Brümmer, and M. Qaim. 2012. "Farmer Participation in Supermarket Channels, Production Technology, and Efficiency: The Case of Vegetables in Kenya." American Journal of Agricultural Economics 94 (4): 891-912.

Reardon, T. 2015. “The Hidden Middle: The Quiet Revolution in the Midstream of Agrifood Value Chains in Developing Countries." Oxford Review of Economic Policy 31 (1): 45-63.

Reardon, T., C. Barrett, J. Berdegué, and J. Swinnen. 2009. “Agrifood Industry Transformation and Small Farmers in Developing Countries." World Development 37 (11): 1717-1727.

Reardon, T., and J. A. Berdegué. 2002. "The Rapid Rise of Supermarkets in Latin America: Challenges and Opportunities for Development." Development Policy Review 20 (4): $317-334$.

Reardon, T., K. Z. Chen, B. Minten, and L. Adriano. 2012. The Quiet Revolution in Staple Food Value Chains in Asia: Enter the Dragon, the Elephant, and the Tiger. Manila: Asian Development Bank; Washington, DC: IFPRI.

Reardon, T., J.-M. Codron, L. Busch, J. Bingen, and C. Harris. 1999. "Global Change in Agrifood Grades and Standards: Agribusiness Strategic Responses in Developing Countries.” International Food and Agribusiness Management Review 2 (3): 195-205.

Reardon, T., R. Echeverría, J. Berdegué, B. Minten, S. Liverpool-Tasie, D. Tschirley, and D. Zilberman. 2019. "Rapid Transformation of Food Systems in Developing Regions: Highlighting the Role of Agricultural Research and Innovations.” Agricultural Systems 172: 47-59. 
Reardon, T., S. Henson, and J. Berdegué. 2007. “'Proactive Fast-Tracking' Diffusion of Supermarkets in Developing Countries: Implications for Market Institutions and Trade." Journal of Economic Geography 7 (4): 1-33.

Reardon, T., C. Hu, D. Tschirley, M. Dolislager, and J. Snyder. 2015. “Urbanization, Diet Change, and Transformation of Food Value Chains in Asia." Report submitted to USAID from the Global Center for Food System Innovation, Michigan State University. June.

Reardon, T., B. Minten, K. Chen, S. Das Gupta, T. A. Dao, J. Wang, and K. A. S. Murshid. 2014. "Tied Output-Credit Markets Have Come Untied: The Fall of Traditional Agrifood Value Chain Finance in Asia." Paper for the Asian Development Bank, Manila, from Michigan State University and IFPRI. August.

Reardon, T., and C. P. Timmer. 2014. "Five Inter-Linked Transformations in the Asian Agrifood Economy: Food Security Implications." Global Food Security 3 (2): 108-117.

Reardon, T., C. P. Timmer, C. B. Barrett, and J. A. Berdegue. 2003. “The Rise of Supermarkets in Africa, Asia, and Latin America." American Journal of Agricultural Economics 85 (5): $1140-1146$.

Reardon, T., D. Tschirley, B. Minten et al. 2015. "Transformation of African Agrifood Systems in the New Era of Rapid Urbanization and the Emergence of a Middle Class." In Beyond a Middle Income Africa: Transforming African Economies for Sustained Growth with Rising Employment and Incomes, edited by O. Badiane and T. Makombe, 62-74. ReSAKSS Annual Trends and Outlook Report 2014. Washington, DC: IFPRI.

Rello, F., and F. Saavedra. 2007. "Implicaciones estructurales de la liberalización en la agricultura y el desarrollo rural. El caso de México.” Report to RuralStruc Project, mimeo, World Bank.

Ricardo, D. 1817. Principles of Political Economy and Taxation. London: John Murray.

Rubey, L. 1995. "The Impact of Policy Reform on Small-Scale Agribusiness: A Case Study of Maize Processing in Zimbabwe." African Rural and Urban Studies 2 (2-3): 93-119.

Saenger, C., M. Torero, and M. Qaim. 2014. "Impact of Third-Party Contract Enforcement in Agricultural Markets-A Field Experiment in Vietnam." American Journal of Agricultural Economics 96 (4): 1220-1238.

Senauer, B., D. Sahn, and H. Alderman. 1986. "The Effect of the Value of Time on Food Consumption Patterns in Developing Countries: Evidence from Sri Lanka." American Journal of Agricultural Economics 68 (4): 920-927.

Simmons, P., P. Winters, and I. Patrick. 2005. “An Analysis of Contract Farming in East Java, Bali, and Lombok, Indonesia." Agricultural Economics 33: 513-525.

Stifel, D., B. Minten, and B. Koru. 2016. "Economic Benefits of Rural Feeder Roads: Evidence from Ethiopia." Journal of Development Studies 52 (9): 1335-1356. 
Swinnen, J., ed. 2007. Global Supply Chains, Standards and the Poor. Wallingford, UK: CABI Press.

Swinnen, J., K. Deconinck, T. Vandemoortele, and A. Vandeplas. 2015. Quality Standards, Value Chains, and International Development: Economic and Political Theory. Cambridge, UK: Cambridge University Press.

Tollens, E. 1997. Wholesale Markets in African Cities: Diagnosis, Role, Advantages, and Elements for Further Study and Development. FAO Food Supply and Distribution to Cities in French-Speaking Africa. Rome: FAO.

Tschirley, D., T. Reardon, M. Dolislager, and J. Snyder. 2015. “The Rise of a Middle Class in Urban and Rural East and Southern Africa: Implications for Food System Transformation.” Journal of International Development 27 (5): 628-646.

Verhofstadt, E., and M. Maertens. 2013. "Processes of Modernization in Horticulture Food Value Chains in Rwanda." Outlook on Agriculture 42 (4): 273-383.

Vernon, R. 1966. “International Investment and International Trade in the Product Cycle." Quarterly Journal of Economics 80 (2): 190-207.

_. 1979. "The Product Cycle Hypothesis in a New International Environment." Oxford Bulletin of Economics and Statistics 41 (4): 255-267.

Wilkinson, J., and R. Rocha. 2009. "Agro-Industry Trends, Patterns and Development Impacts." In Agro-Industries for Development, edited by C. A. da Silva, D. Baker, A. W. Shepherd, C. Jenane, and S. Miranda-da-Cruz, 46-92. FAO/UNIDO/IFAD. Wallingford, UK: CAB International.

Williamson, O.E. 1979. "Transaction-Cost Economics: The Governance of Contractual Relations." Journal of Law and Economics 22 (2): 233-261.

_ 1981. "The Economics of Organization: The Transaction Cost Approach." American Journal of Sociology 87 (3): 548-577.

Yi, D., and T. Reardon. 2015. "Allocative Efficiency of Agrifood Traders: Shrimp Traders in Indonesia." Bulletin of Indonesian Economic Studies (3): 405-423.

Zhang, Y., X. Rao, and H. H. Wang. 2019. “Organization, Technology, and Management Innovations through Acquisition in China's Pork Value Chains: The Case of the Smithfield Acquisition by Shuanghui." Food Policy 83: 337-345.

Zilberman, D., L. Lu, and T. Reardon. 2019. "Innovation-Induced Food Supply Chain Design.” Food Policy 83: 289-297. 
